\title{
Analysis of the Impact of Accounting Information Systems (AIS) on Organizational Effectiveness
}

\author{
Dr. Mouhamadou Sow, DBA, MBA, CFE, CRMA \\ Adjunct Faculty Member, University of Phoenix, Tempe, AZ, USA \\ Adjunct Faculty, Grand Canyon University, Phoenix, AZ, USA \\ Faculty Member, National American University, Rapid City, SD, USA \\ Adjunct Faculty, University of Saint Mary, Leavenworth, KS, USA
}

Received: January 2, 2021 Accepted: February 7, 2021 Published: February 25, 2021

doi:10.5296/ber.v11i1.18140ＵRL: https://doi.org/10.5296/ber.v11i1.18140

\begin{abstract}
The purpose of the study was to examine how AIS is observed by its users within an academic medical center where financial transactions are critical in managing patient care and research operations. A cross-sectional qualitative research design was applied using interviews, the convenience sampling method was used to select study participants, and a thematic analysis was conducted to identify patterns in the responses given. Based on the results provided in the interviews, 1) AIS design and specifications are associated with user satisfaction and performance in the workplace environment. 2) Organizations must focus on delivering AIS that offers the resources required for employees to perform their roles and being as effective as possible. 3) User needs should be identified as part of any AIS implementation or upgrade to support performance optimization with ongoing system utilization. The study questions were validated under the subject matter of job-related tasks and performance as related to the use of accounting information system. The study will aid the future business environment by obtaining employee feedback regarding future changes to the system that will address their specific roles and responsibilities so that the system promotes greater efficiency and will enhance performance.
\end{abstract}

Keywords: accounting information systems, academic medical center, contingency theory, a model of information systems success

\section{Introduction}

Accounting information systems (AIS) are essential to organizational operations and all activities related to financial management. Organizations are obligated to exercise transparency in their financial decisions, and access to financial records is critical to forecast 
models, establish budgets based upon existing cashflows, and direct financial resources appropriately. Performance measurements require accounting systems that apply advanced technologies and strengthen performance by protecting resources and ensuring that all aspects of financial accountability are in order (Naser \& Al Shobaki, 2016). Organizations must focus on applying the data available through AIS to solve problems and make future strategic decisions, and this practice requires the utilization of existing systems to evaluate their capabilities and their impact on performance (Al-Mamary, Shamsuddin, \& Aziati, 2014). Understanding the levels of user satisfaction of AIS as part of financial operations requires an evaluation of the quality and data transparency within these systems and how they impact individual performance (Hahn, Wanjala, \& Marx, 2013). From the perspective of employees, it is necessary to acknowledge the issues faced when using AIS to conduct business transactions and how employees perceive the system and its impact on performing their work duties and responsibilities.

The study identified the ongoing risks associated with the implementation of an accounting information system that does not satisfy user needs and contributes to poor productivity in the workplace. It was important to identify the concerns among employees regarding the system and its specifications to determine the impact of the system on employee performance outcomes. The trickle-down effect of a poorly designed or inefficient system can have detrimental effects on the organization on many levels and can cause harm because employee performance will decline over time if they lack the motivation and the tools to be successful.

For the study, the following research questions were proposed:

1) What was the effect of the selected accounting information system on employee performance in the workplace environment?

2) What was the relationship between the specifications of the current AIS system and its effects on employee performance?

3) Did the AIS limit the ability of employees to be productive and to focus on the needs of the organization?

4) Was the current AIS system counterintuitive or impractical?

5) How did the AIS system affect employee motivation to perform effectively on the job?

\section{Literature Review}

Accounting information systems facilitate many financial transactions and allow for the storage and retrieval of data points in real-time. Many systems are equipped with customizations that support organizational needs, while others provide standardized options for collecting data and reporting functions. System performance and user-friendliness have an impact on employee performance because they affect how employees use the system when they are comfortable with its features, and if they know how to manage data in effective ways (Hariyati, Tjahjadi, \& Soewarno, 2018). Among organizations, AIS should emphasize the quality of the information entered, the integrity of the data, and the quality of the entire system through its effects on operations (Ali, Omar, \& Bakar, 2016). The data entered in an accounting system is expected to be accurate because it drives numerous financial transactions and decisions; however, when many users input data, there is a risk of errors and 
the integrity of the data is diminished.

The balanced scorecard theory indicates that decision-making that is largely driven by data analytics from an AIS influence performance and affect operations; therefore, organizations must focus on systems that support practical data collection and accuracy to support positive performance (Appelbaum, Kogan, Vasarhelyi, \& Yan, 2017; Grigoroudis, Orfanoudaki, \& Zoponunidis, 2012). In healthcare organizations, there must be a greater emphasis on financial transactions that are related to purchasing, patient care, research, and other operations (Eldenburg, Krishnan, \& Krishnan, 2017). The system should provide the necessary features to advance accounting and financial controls for all aspects of the organization to prevent waste, fraud, and other errors (Eldenburg et al., 2017). With any system, its employees should have a clear understanding of its capabilities and how it is used for specific purposes, and its functionality should be managed effectively across all levels. The organization and its leadership team have a responsibility to manage the ownership of all components of the system across departments and divisions to ensure that it is managed and is fully operational at all levels (Shabab \& Nisa, 2014).

As healthcare information systems become more complex, user satisfaction is an important issue to achieve greater effectiveness and support user goals and objectives (Chang, Chen, \& Lan, 2012; Rubel \& Kee, 2014). As organizations expand in scope and their information systems expand to meet these demands, the system specifications and data management should provide value to employees to drive their effectiveness and meet expectations (Chang et al., 2012). If employees in healthcare organizations lack faith, trust, or understanding of these systems and they affect their work performance, their user and job satisfaction may diminish and their performance may decline (Chang et al., 2012; Huang et al., 2014). Specifically, academic medical centers conduct research, provide education, and offer comprehensive clinical care to patients using technologies and the knowledge of expert practitioners to address a variety of health concerns. The study determined if the quality of the system had an impact on the quality of service and its utilization in understanding employees' level of satisfaction with the system and its effects on motivation to achieve high-level performance (Aguilar-Escobar, Bourque, \& Godino-Gallego, 2015).

Exercising greater control over system management is vital to the success of these systems and their impact on employee performance, and when these systems are difficult to use, employees may experience greater frustration that could contribute to negative performance measures (Hammad, Jusoh, \& Oon, 2010; Artawijaya \& Darma, 2015). Among managers and at other levels of the healthcare organization, performance is often associated with the use of these systems because users must know how to enter data, obtain reports, and use other functions as part of their routine roles and responsibilities (Hammed et al., 2010). The usability of the system and its components impacts satisfaction rates among users, and if a system is not customized to meet specific standards, it is less impactful and effective in managing financial needs (Agglidis, Prodromos, \& Chatzoglou, 2012). Lack of training, a system with impractical features, lack of technical support, and a limited association in functionality to current needs are key reasons employees may not have a strong affinity for the system and do not believe that it serves the needs of the organization well (Mihail \& 
Kloutsiniotis, 2016; Khalifa, 2014).

In healthcare organizations such as hospitals or academic medical centers, cost accounting and key controls are vital, and all related system components should offer the tools required to be successful in maintaining accuracy within the system and in any reporting that is necessary (Carroll \& Lord, 2016; Wager, Lee, \& Glaser, 2009). Transparency is vital for organizations to promote high-quality services to patients and in all other areas; for these organizations, it is important for all systems to reflect the appropriate cost accounting measures and to enable employees to enter and edit information as needed, which will ensure that accuracy and transparency are prioritized (Carroll \& Lord, 2016). By extension, the organization must have accounting systems in place, which will promote data integrity and provide as much transparency as possible to allow employees to perform with greater accuracy and professionalism.

\section{Method}

A cross-sectional qualitative research design using interviews was conducted with employees within a large academic medical center using the convenience sampling method (Chang et al., 2012). This design was appropriate for the study because it involved the collection of data from employees regarding their individual experiences with the AIS system at their organization. The study sought to determine if employees are satisfied with the AIS system currently in place, including its positive and negative components and the ability of the system to enable employees to perform their roles. It was expected that their actions should be a positive reflection of the systems that are currently available, but if these systems are inaccurate, inefficient, or impractical, performance will falter, and the organization will fail to meet expectations.

The interview structure was designed to address employees' understanding of the AIS as it is currently structured, the frequency of use, and its impact on their roles. The interviews were structured in nature to address questions regarding the basic roles and responsibilities of each participant at work and their frequency of use of the system and to analyze if it had a positive impact on their current roles. The inclusion criteria were any employees who work in any department at the academic medical center that involves accounting, finance, and purchasing functions and was responsible for using the current accounting information system. The exclusion criteria were employees who did not use the system as part of their regular roles. This group of participants provided feedback regarding their personal experiences with the system and how it affects their roles.

The interview questions were largely associated with the job and the use of the accounting information systems, and the subject matter increases the validity of the questions and their relevance to the study. Prior to conducting the study, it was also necessary to obtain the required approval from the Institutional Review Board (IRB), including the approval of informed consent documents to ensure that all participants understood the study and its risks, and could withdraw from the study at any time. A thematic analysis was conducted to determine patterns in responses, including the perceptions of participants who use the system. 


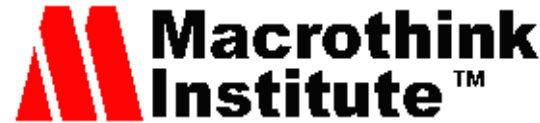

Business and Economic Research ISSN 2162-4860 2021, Vol. 11, No. 1

Following the primary objectives of AIS, contingency theory was applied to this framework to promote the ideal "fit" between system and organization, and by extension, the employees (Hammad et al., 2010, p. 767). Contingency theory supported the premise that organizational differences drives system needs and specifications as well as subsequent training and usability of the system; each of these factors also contributed to employee knowledge of the system and individual performance (Hammad et al., 2010). The organization emphasized delivering a product/system that was aligned with organizational needs to its employees and offered the resources needed to enhance performance. The failure of the system to fully capture and align with organizational needs would lead to poor performance, which is not only a product of employee performance but would also increase costs and reduce productivity.

For this study, the model of information systems success by DeLone \& McLean was used to examine service quality and its impact on user satisfaction to achieve optimal job performance (Chang et al., 2012). This model included a focus on service quality as part of system performance and its impact on employees to achieve their goals at the organization (Chang et al., 2012). With this framework, the primary characteristics involved in evaluating the system included its accessibility for employees as they attempt to manage their roles and perform their required duties, usability in the form of understanding how to use the website and if its features are readily accepted or understood, navigation which allows employees to obtain or enter information with the appropriate links available, and interactivity, which supports the personalization of the study for the specific needs of the organization (Chang et al., 2012).

\section{Results}

A total of 14 employees participated in the study; at its onset, 15 participants were selected but one withdrew before the interview. The study population included employees with different levels of experience with the accounting information system. This diversity in participants and their responses offered greater insight into the system and its effectiveness from many angles. All 14 study participants had at least limited experience with the system, with an experience range of one to ten years.

From the 14 study participants, the following data was collected:

1) Years of employment at the organization:

a. $1-2$ years: 21.4 percent $(n=3)$

b. $3-5$ years: 42.8 percent $(n=6)$

c. 6-9 years: 14.2 percent $(n=2)$

d. 10 years or more: 21.4 percent $(n=3)$

2) Number of years of experience using the AIS:

a. 1-2 years: 21.4 percent $(n=3)$

b. $3-5$ years: 35.7 percent $(n=5)$

c. 6-9 years: 21.4 percent $(n=3)$

d. 10 years or more: 21.4 percent $(n=3)$

3) The division they were employed in: 
a. Accounting (patient care or research): 42.8 percent $(n=6)$

b. Finance: 35.7 percent $(n=5)$

c. Other financial functions (i.e., purchasing): 21.4 percent $(n=3)$

In the study, other themes identified through the interviews include the following: 1) The majority of study participants (78.6 percent; $n=11$ ) were not fully satisfied with the system and its specifications; 2) nearly all participants (92.9 percent; $n=13$ ) believe that some components of the system are cumbersome and require the performance of additional unnecessary tasks; and 3) almost all participants (92.9 percent; $n=13$ ) acknowledged that the system requires additional changes or customizations to become more user friendly for employees; and 4) half of all participants (50 percent; $n=7$ ) acknowledged that the system in its current state can negatively impact their motivation to perform their work.

\section{Discussion}

Regarding research question \#1, the system did not provide an efficient portal for employees to perform at the anticipated levels. With the current system, its limitations are problematic for employees, and their responses indicate that their motivation to perform consistently at a high level is affected by the negative aspects of the system. In addressing research question \#2, almost all participants believed that the system is flawed in one way or the other, including some of its specifications and its limitations. Regarding research question \#3, AIS was a limiting factor in meeting employee productivity objectives and in enabling employees to emphasize organizational needs. Regarding research question \#4, the current AIS system was not fully counterintuitive and had numerous impractical components that made it difficult for employees to manage their work in a time-efficient manner. Finally, regarding research question \#5, the AIS system had an overall negative impact on employee motivation due to the ongoing frustration with the current system and some of its components.

The study demonstrated the importance of information systems for finance and accounting that are appropriate and practical for health care systems, such as academic medical centers. The system specifications were critical in determining how employees respond to the system, if they found it useful, and if they understood how to improve their work performance by using this system regularly. The feedback provided by employees was instrumental in determining areas where the system value was limited. Based on the information collected, the organization determined how the system limited employee performance.

The future success of the organization and its ability to provide control, oversight, and proper data collection related to accounting and finance depends on the delivery of system tools and specifications that will make a difference for employees in alleviating some of the stressors of their roles and will also promote greater efficiency if they do not have to take on extra processes or steps that negatively affect performance (Khodambashi, 2013). An academic medical center has a responsibility to provide its employees with systems that are fully integrated to manage a variety of functions related to research, patient care, and education across different areas. This information provided employees with a set of resources that are valuable in meeting their needs and will demonstrate that the system is fully functional, and its features are appropriate. The outcomes of the study indicate that feedback from employees 
regarding their use of the system, its impact on their daily activities, and other missing components affect motivation and performance.

\section{Conclusion}

The study offered employee insights regarding the significance of accounting information systems and their role in achieving performance goals as they are tied to motivation. With the interviews, the feedback generated from participants was important in assessing the system and its current functionality. The application of contingency theory was useful because it provided context regarding the perceived needs of the organization and the ability of the current system to meet these needs effectively (Piening, Baluch, \& Salge, 2013). It is recognized that the current system and its capabilities are less than satisfactory and harm employee performance and motivation. The feedback obtained through the interviews offered greater insight into employees' understanding and acceptance of the system and their ability to meet organizational needs in its current state (Nadri et al., 2018).

The study limitations included the following: the study was conducted at a single organization, an academic medical center. Since the study is limited to one site, the results play a role in shaping future studies on this subject matter. Researchers must further examine the issues affecting the study and the outcomes that will likely promote change and progress to align system features with current strategic needs. They will also contribute to future outcomes of the organization and in focusing on how employee performance is largely a product of system features, benefits, and limitations that affect how they perform their daily activities and if they achieve full accuracy in their work.

\section{References}

Abu-Naser, S. S., \& Al Shobaki, M. J. (2016). Computerized Management Information Systems Resources and their Relationship to the Development of Performance in the Electricity Distribution Company in Gaza. [Online] Available:

http://dstore.alazhar.edu.ps/xmlui/bitstream/handle/123456789/119/ABUCMR.4.pdf?sequenc $\mathrm{e}=1 \&$ is Allowed $=\mathrm{y}$

Aggelidis, V. P., \& Chatzoglou, P. D. (2012). Hospital information systems: Measuring end-user computing satisfaction (EUCS). Journal of Biomedical Informatics, 45(3), 566-579. https://doi.org/10.1016/j.jbi.2012.02.009

Aguilar-Escobar, V. G., Bourque, S., \& Godino-Gallego, N. (2015). Hospital kanban system implementation: Evaluating satisfaction of nursing personnel. Investigaciones Europeas de Dirección y Economía de la Empresa, 21(3), 101-110.

https://doi.org/10.1016/j.iedee.2014.12.001

Ali, B. J., Omar, W. A. W., \& Bakar, R. (2016). Accounting Information System (AIS) and organizational performance: Moderating effect of organizational culture. International Journal of Economics, Commerce and Management, 4(4), 138-158. [Online] Available: https://www.researchgate.net/profile/Wan_Ahmad_Wan_Omar/publication/303247197_Intern ational_Journal_of_Economics_Commerce_and_Management_ACCOUNTING_INFORMA 
TION_SYSTEM_AIS_AND_ORGANIZATIONAL_PERFORMANCE_MODERATING_E FFECT_OF_ORGANIZATIONAL_CULTURE/links/5739e46b08aea45ee83f72d4/Internatio nal-Journal-of-Economics-Commerce-and-Management-ACCOUNTING-INFORMATION-S YSTEM-AIS-AND-ORGANIZATIONAL-PERFORMANCE-MODERATING-EFFECT-OFORGANIZATIONAL-CULTURE.pdf

Al-Mamary, Y. H., Shamsuddin, A., \& Abdul Hamid, N. A. (2014). Factors affecting the successful adoption of management information systems in organizations towards enhancing organizational performance. American Journal of Systems and Software, 2(5), 121-126.

Appelbaum, D., Kogan, A., Vasarhelyi, M., \& Yan, Z. (2017). Impact of business analytics and enterprise systems on managerial accounting. International Journal of Accounting Information Systems, 25, 29-44. http://dx.doi.org/10.1016/j.accinf.2017.03.003

Artawijaya, I. G. P. A., \& Darma, G. S. (2015). Evaluation the effectivity of performance management online system to improving the employees performance. Jurnal Manajemen Bisnis, 12(2), 73-89. [Online] Available:

http://journal.undiknas.ac.id/index.php/magister-manajemen/article/viewFile/296/252

Carroll, N., \& Lord, J. C. (2016). The growing importance of cost accounting for hospitals. Journal of Health Care Finance, 43(2), 172. [Online] Available:

https://www.ncbi.nlm.nih.gov/pmc/articles/PMC6910125/

Chang, C. S., Chen, S. Y., \& Lan, Y. T. (2012). Motivating medical information system performance by system quality, service quality, and job satisfaction for evidence-based practice. BMC Medical Informatics and Decision Making, 12(1), 135.

https://doi.org/10.1186/1472-6947-12-135

Eldenburg, L. G., Krishnan, H. A., \& Krishnan, R. (2017). Management accounting and control in the hospital industry: A review. Journal of Governmental \& Nonprofit Accounting, 6(1), 52-91. https://doi.org/10.2308/ogna-51922

Grigoroudis, E., Orfanoudaki, E., \& Zopounidis, C. (2012). Strategic performance measurement in a healthcare organisation: A multiple criteria approach based on a balanced scorecard. Omega, 40(1), 104-119. https://doi.org/10.1016/j.omega.2011.04.001

Hahn, D., Wanjala, P., \& Marx, M. (2013). Where is information quality lost at clinical level? A mixed-method study on information systems and data quality in three urban Kenyan ANC clinics. Global health action, 6(1), 21424. https://doi.org/10.3402/gha.v6i0.21424

Hammad, S. A., Jusoh, R., \& Oon, E. Y. N. (2010). Management accounting system for hospitals: a research framework. Industrial Management \& Data Systems, 110(5), 762-784. https://doi.org/10.1108/02635571011044777

Hariyati, H., Tjahjadi, B., \& Soewarno, N. (2019). The mediating effect of intellectual capital, management accounting information systems, internal process performance, and customer performance. International Journal of Productivity and Performance Management. https://doi.org/10.1108/IJPPM-02-2018-0049 
Huang, L. C., Ahlstrom, D., Lee, A. Y. P., Chen, S. Y., \& Hsieh, M. J. (2016). High-performance work systems, employee well-being, and job involvement: An empirical study. Personnel Review. https://doi.org/10.1108/PR-09-2014-0201

Khalifa, M. (2014). Technical and human challenges of implementing hospital information systems in Saudi Arabia. Journal of Health Informatics in Developing Countries, 8(1). [Online] Available: https://jhidc.org/index.php/jhidc/article/download/111/153

Khodambashi, S. (2013). Business process re-engineering application in healthcare in a relation to health information systems. Procedia Technology, 9(2212), 949-957.

https://doi.org/10.1016/j.protcy.2013.12.106

Mihail, D. M., \& Kloutsiniotis, P. V. (2016). The effects of high-performance work systems on hospital employees' work-related well-being: Evidence from Greece. European Management Journal, 34(4), 424-438. https://doi.org/10.1016/j.emj.2016.01.005

Nadri, H., Rahimi, B., Afshar, H. L., Samadbeik, M., \& Garavand, A. (2018). Factors affecting acceptance of hospital information systems based on extended technology acceptance model: A case study in three paraclinical departments. Applied Clinical Informatics, 9(2), 238. https://doi.org/10.1055/s-0038-1641595

Piening, E. P., Baluch, A. M., \& Salge, T. O. (2013). The relationship between employees' perceptions of human resource systems and organizational performance: Examining mediating mechanisms and temporal dynamics. Journal of Applied Psychology, 98(6), 926. https://doi.org/10.1037/a0033925

Rubel, M. R. B., \& Kee, D. M. H. (2014). Quality of work-life and employee performance: Antecedent and outcome of job satisfaction in Partial Least Square (PLS). World Applied Sciences Journal, 31(4), 456-467.

Shahab, M. A., \& Nisa, I. (2014). The influence of leadership and work attitudes toward job satisfaction and performance of the employee. International Journal of Managerial Studies and Research, 2(5), 69-77. [Online] Available:

http://citeseerx.ist.psu.edu/viewdoc/download?doi=10.1.1.678.2858\&rep=rep1\&type=pdf

Wager, K. A., Lee, F. W., \& Glaser, J. P. (2017). Health Care Information Systems: A Practical Approach for Health Care Management. John Wiley \& Sons.

\section{Appendix}

\section{Appendix A: Interview Questions}

1. What is your age group?
a. $18-29$
b. $30-49$
c. 50-65
d. 65 and over 
2. How long have you worked at the organization?

3. What is your current role?

4. What is your highest level of education?
a. High School Diploma
b. Bachelor's Degree
c. Master's Degree
d. Other Advanced Degree (MD, Ph.D., etc.)

5. What is your level of experience working with accounting information systems?

6. What types of challenges have you experienced with accounting information systems?

7. What is your perspective regarding the accounting knowledge that is necessary for the proper recording and processing of transactions?

8. Does your organization provide training to provide updated accounting knowledge?

9. Is accounting knowledge a critical component in the implementation of an accounting information system?

10. Does accounting knowledge increase organizational performance and managerial support?

11. Is managerial support a pre-condition to implement an accounting information system?

12. In a managerial role, do you support the proper implementation of an accounting information system as part of the enterprise?

13. In a managerial role, are you willing to invest to implement and operate a fully functional accounting information system as part of the enterprise?

14. In a managerial role, does a fully functional and effective accounting information system reduce inefficiency and increase performance?

15. Does the accounting information system require updating to meet goals and objectives?

\section{Copyright Disclaimer}

Copyright for this article is retained by the author(s), with first publication rights granted to the journal.

This is an open-access article distributed under the terms and conditions of the Creative Commons Attribution license (http://creativecommons.org/licenses/by/4.0/). 